UDK 528.14

\title{
PSEUDOATSTUMŲ IR NEŠLIO FAZIŲ SĄLYGINIŲ LYGČIŲ SU PAPILDOMAIS PARAMETRAIS TAIKYMAS GPS MATAVIMU REZULTATAMS APDOROTI
}

\author{
Jonas Skeivalas \\ Geodezijos ir kadastro katedra, Vilniaus Gedimino technikos universitetas, \\ Saulètekio al.11,LT-10223 Vilnius - 40,Lietuva, el.paštas: Jonas.Skeivalas@ap.vtu.lt
}

Iteikta 200402 20, priimta 20040614

\begin{abstract}
Santrauka. Straipsnyje analizuojami metodai pseudoatstumų ir nešlio fazių matavimų rezultatams apdoroti, naudojant dviejų ir trijų nešlio dažnių GPS imtuvus. Čia taikomos pseudoatstumų ir nešlio fazių sąlyginès lygtys su papildomais parametrais, sudaromos kiekvienoje epochoje pagal kiekvieno „matomo“ palydovo signalu matavimo rezultatus. Siūlomu metodu galima patikimai eliminuoti atsitiktines ir sistemingąsias matavimų klaidas, kurių pagrindinè priežastis - troposferos ir jonosferos įtaka.
\end{abstract}

Raktažodžiai: GPS, pseudoatstumai, nešlio fazès, jonosferos klaidos, mažiausiujų kvadratų metodas.

\section{Ivadas}

GPS matavimo rezultatu tikslumui itakos turi daugelis veiksnių: dirbtinių Žemès palydovų (DŽP) efemeridžių klaidos, DŽP geometrija, GPS imtuvų ir palydovų laikrodžiuc klaidos, signalų interferencija ir atspindžiai, troposfera, jonosfera bei kitos šaltinių klaidos. Didžiausios įtakos GPS matavimų tikslumui turi troposfera ir jonosfera. Nemaža autoriu itvairiais aspektais analizavo ir analizuoja minètas matavimų klaidas, atitinkamų dydžių ir parametrų nustatymo tikslumą, kaip sudaromi skaičiavimo algoritmai [1-10]. Dažniausiai jonosferos itakai matavimo rezultatuose eliminuoti taikomi dviejų nešlio dažnių tiesiniai modeliai, o troposferos itakai sumažinti - atitinkami netiesiniai modeliai.

Straipsnyje siūlomas metodas pagrịstas sąlyginių lygčiuc su papildomais parametrais taikymu pseudoatstumų ir nešlio fazių matavimų rezultatams apdoroti. Sąlyginès lygtys sudaromos taikant du arba tris nešlio dažnius ir sprendžiamos mažiausiujuc kvadratų metodu. Taikant papildomus parametrus matavimų klaidų sistemingoji komponente eliminuojama patikimiau.

\section{Metodo esmè}

GPS matavimo kanaluose $L 1$ ir $L 2$ rezultatai, t. y. pseudoatstumu ir nešlio fazių reikšmès, nesutampa pagrindinai dèl jonosferos, troposferos lemiamų ir kitu matavimo klaidu. Kadangi ir dèl jonosferos, ir dèl kitų šaltinių itakos atsirandančios matavimo klaidos turi atsitiktines ir sistemingąsias komponentes, tai matavimo rezultatams apdoroti taikysime mažiausiuju kvadratų metodą su papildomais parametrais.

\section{Pseudoatstumų variantas}

Išmatuotiems $L 1$ ir $L 2$ kanaluose taikant du nešlio dažnius pseudoatstumams $R_{i, a}^{k}(t)$ - vienos epochos ir vieno palydovo - galime parašyti vieną sąlyginę lygti su vienu papildomu parametru $\tau_{i}$ :

$$
\tilde{R}_{1, a}^{k}(t)-\tilde{R}_{2, a}^{k}(t)+\tau_{i}=0,
$$

čia $\quad \tilde{R}_{i, a}^{k}(t)=R_{i, a}^{k}(t)+v_{R_{i}}-\quad i$-ojo kanalo išlyginta pseudoatstumo tarp palydovo $k$ ir imtuvo a laiko momentu $t$ reikšmè, $R_{i, a}^{k}(t)$ - išmatuota $i$-ojo kanalo pseudoatstumo reikšmè, $\quad v_{R_{i}}-i$-ojo kanalo pseudoatstumo paklaidų dèl atsitiktinių matavimo klaidų (jonosfera, troposfera ir kt. veiksniai) pataisa, $\tau_{i}-$ papildomas parametras, ivertinantis sistemingają komponentę.

Lygybę (1) galime išreikšti sąlyginès pataisų lygties pavidalu:

$$
v_{R_{1}}-v_{R_{2}}+\tau_{i}+\omega_{i}=0,
$$

čia $\omega_{i}=R_{1, a}^{k}(t)-R_{2, a}^{k}(t)$ - laisvasis narys, arba nesąryšis.

Sąlyginių pataisų lygčių sistema, panaudojus vieno palydovo signalų matavimo rezultatus $r$ epochose:

$$
A \mathbf{v}_{R}+C \tau+\omega=0
$$

čia $\boldsymbol{A}$ - sąlyginių lygčių koeficientų (kai pataisos atsitiktinès) matrica, $\boldsymbol{C}$ - salyginių lygčių koeficientų esant sistemingiesiems parametrams matrica, $\mathbf{v}_{\boldsymbol{R}}-$ atsitiktinių pataisu vektorius, $\boldsymbol{\tau}$ - sisteminguju parametru vektorius, $\boldsymbol{\omega}=R_{1}(t)-R_{2}(t)=\boldsymbol{A} \boldsymbol{R}(t)$ - nesąryšių vektorius, $\quad \boldsymbol{R}(t)=\left\{R_{1}^{T}(t), R_{2}^{T}(t)\right\}^{T} . \quad \boldsymbol{R}_{1}(t), \boldsymbol{R}_{2}(t)-L 1$ ir $L 2$ kanalų išmatuotų pseudoatstumų vektoriai. Tokias lygčių sistemas galima parašyti remiantis kiekvieno „matomo“ 
palydovo signalų matavimo rezultatais. Pagal kiekvieną palydovą sudarytas sąlyginių pataisų lygčių sistemas galima laikyti nepriklausomomis ir spręsti nepriklausomai vieną nuo kitos.

Kadangi sisteminguju parametrų skaičius $s$ neturi viršyti matricos $A$ rango $r$, tai matricos $C$ stulpelių skaičius neturi būti didesnis už $r$, t. y. $s \leq r$, o eilučiu skaičius yra lygus matricos $A$ eilučiu skaičiui $r$. Taigi kiekviena sąlyginè lygtis gali turèti ne daugiau kaip vieną sistemingaji parametrą.

Sąlyginių pataisų lygčių sistemą (3) sprendžiame mažiausiujų kvadratų metodu, taikydami sąlygą

$$
\Phi=\mathbf{v}_{R}^{T} \boldsymbol{P}_{R} \mathbf{v}_{R}-2 \boldsymbol{k}^{T}\left(A \mathbf{v}_{R}+\boldsymbol{C} \boldsymbol{\tau}+\boldsymbol{\omega}\right)=\min ,
$$

čia $\boldsymbol{P}_{R}=\left(\boldsymbol{P}_{1}, \boldsymbol{P}_{2} \ldots, \boldsymbol{P}_{r}\right)_{\text {diag }}-$ išmatuotu pseudoatstumu svorių istrižinè matrica, $\boldsymbol{P}_{i}=\left(p_{R_{1}}, p_{R_{2}}\right)_{\text {diag }}-i$-osios epochos blokinè svorių matrica, $k$ - Lagranžo koeficientų (koreliatu) vektorius.

Normalinių lygčių sistemos išraiška:

$$
\boldsymbol{N}_{0}\left(\begin{array}{l}
\boldsymbol{k} \\
\boldsymbol{\tau}
\end{array}\right)+\left(\begin{array}{c}
\boldsymbol{\omega} \\
0
\end{array}\right)=0
$$

čia $\quad \boldsymbol{N}_{0}=\boldsymbol{A}_{0} \boldsymbol{P}_{R}^{-1} \boldsymbol{A}_{0}^{T}=\left(\begin{array}{cc}\boldsymbol{N} & \boldsymbol{C} \\ \boldsymbol{C}^{T} & 0\end{array}\right), \quad N=A P_{R}^{-1} A^{T}$, $\boldsymbol{A}_{0}=(\boldsymbol{A C})$.

Sistemos sprendinys -

$$
\left(\begin{array}{c}
\boldsymbol{k} \\
\boldsymbol{\tau}
\end{array}\right)=-\boldsymbol{N}_{0}^{-1}\left(\begin{array}{c}
\boldsymbol{\omega} \\
0
\end{array}\right)
$$

arba

$$
\begin{aligned}
& \boldsymbol{k}=-\boldsymbol{N}^{-1}(\boldsymbol{C} \boldsymbol{\tau}+\boldsymbol{\omega}), \\
& \boldsymbol{\tau}=-\boldsymbol{N}_{c}^{-1} \boldsymbol{C}^{T} \boldsymbol{N}^{-1} \boldsymbol{\omega},
\end{aligned}
$$

čia $\boldsymbol{N}_{c}=\boldsymbol{C}^{T} \boldsymbol{N}^{-1} \boldsymbol{C}$.

Pataisu vektorius $\mathbf{v}_{R}$ yra lygus

$$
\mathbf{v}_{R}=\boldsymbol{P}_{R}^{-1} \boldsymbol{A}^{T} \boldsymbol{k}
$$

Atvirkštinei matricai $\boldsymbol{N}_{0}^{-1}$ skaičiuoti galima taikyti Frobeniuso išraišką [10]:

$$
\begin{aligned}
& \boldsymbol{N}_{0}^{-1}=\left(\begin{array}{cc}
\boldsymbol{N} & \boldsymbol{C} \\
C^{T} & 0
\end{array}\right)^{-1}= \\
& =\left(\begin{array}{c|c}
\boldsymbol{N}^{-1}-\boldsymbol{N}^{-1} \boldsymbol{C} \boldsymbol{N}_{C}^{-1} C^{T} \boldsymbol{N}^{-1} & \frac{\boldsymbol{N}^{-1} \boldsymbol{C} \boldsymbol{N}_{C}^{-1}}{-\boldsymbol{N}_{C}^{-1}}
\end{array}\right) .
\end{aligned}
$$

Tuomet iš lygybès (6) nustatome

$$
\left(\begin{array}{l}
\boldsymbol{\tau} \\
\tau
\end{array}\right)=-\left(\begin{array}{c}
N^{-1}-N^{-1} C N_{C}^{-1} C^{T} N^{-1} \\
N_{C}^{-1} C^{T} N^{-1}
\end{array}\right) \omega
$$

Kadangi pseudoatstumų matavimo rezultatams, taikant skirtingus nešlio dažnius, didžiausios įtakos turi jonosfera, tai svoriams skaičiuoti taikytos jonosferos itakos vertinimo formulès [3-5]:

$$
\boldsymbol{P}_{i}=\left(p_{R_{1}}, p_{R_{2}}\right)_{\text {diag }}=(1,00 ; 0,368)_{\text {diag }} .
$$

Išlygintų pseudoatstumų vektoriaus $\tilde{\boldsymbol{R}}(t)$ reikšmė skaičiuojama pagal iprastinę formulę:

$$
\tilde{\boldsymbol{R}}(t)=\boldsymbol{R}(t)+\mathbf{v}_{R}=\boldsymbol{R}(t)+\boldsymbol{P}_{R}^{-1} \boldsymbol{A}^{T} \boldsymbol{k} .
$$

Toliau, taikydami koreliatų vektoriaus $\boldsymbol{k}$ išraišką iš formulès (11), rašome:

$$
\tilde{\boldsymbol{R}}(t)=\boldsymbol{R}(t)-\boldsymbol{P}_{R}^{-1} \boldsymbol{A}^{T} \boldsymbol{H} \boldsymbol{\omega}=\left(\boldsymbol{E}-\boldsymbol{P}_{R}^{-1} \boldsymbol{A}^{T} \boldsymbol{H} \boldsymbol{A}\right) \boldsymbol{R}(t),
$$

čia $H=N^{-1}-N^{-1} C N_{C}^{-1} C^{T} N^{-1}, \omega=A R(t)$.

Išlygintų pseudoatstumų vektoriaus $\tilde{\boldsymbol{R}}(t)$ kovariacijų matrica $\boldsymbol{K}_{\tilde{R}}$ nustatoma, taikant atitinkamus matematinès statistikos dèsnius:

$$
\begin{aligned}
& \boldsymbol{K}_{\tilde{R}}=\left(\boldsymbol{E}-\boldsymbol{P}_{\boldsymbol{R}}^{-1} \boldsymbol{A}^{T} \boldsymbol{H A}\right) \boldsymbol{K}_{R}\left(\boldsymbol{E}-\boldsymbol{P}_{R}^{-1} \boldsymbol{A}^{T} \boldsymbol{H} \boldsymbol{A}\right)^{T}= \\
& =\sigma_{0}^{2}\left(\boldsymbol{P}_{\boldsymbol{R}}^{-1}-\boldsymbol{P}_{\boldsymbol{R}}^{-1} \boldsymbol{A}^{T} \boldsymbol{H} \boldsymbol{A} \boldsymbol{P}_{\boldsymbol{R}}^{-1}\right)=\sigma_{0}^{2} \boldsymbol{Q}_{\tilde{R}},
\end{aligned}
$$

čia $\sigma_{0}-$ matavimo rezultato, kurio svoris lygus vienetui, standartinis nuokrypis, $\boldsymbol{K}_{R}=\sigma_{0}^{2} \boldsymbol{P}_{R}^{-1}, \quad Q_{\tilde{R}}-$ vektoriaus $\tilde{R}(t)$ svorinè matrica.

Sąlyginių lygčių koeficientų stačiakampè matrica $\boldsymbol{A}$ pagal $r$ epochų ir pavienio palydovo signalų matavimo rezultatus, kai naudojami du nešlio kanalai - $L 1$ ir $L 2$, yra kvazidiagonaliojo pavidalo:

$$
\boldsymbol{A}=\left(\begin{array}{llll}
\boldsymbol{A}_{1} & & & \\
& \boldsymbol{A}_{2} & & \\
& & \cdots & \\
& & & \boldsymbol{A}_{r}
\end{array}\right),
$$

čia matricos $\boldsymbol{A}$ eilučių skaičius lygus $r$, o stulpelių skaičius $-2 r, \quad \boldsymbol{A}_{i}=(1-1)-i$-osios epochos blokinè matrica, $i=1,2, \ldots, r$.

Sąlyginių lygčių koeficientų esant sistemingiesiems parametrams $\boldsymbol{\tau}$ matrica $\boldsymbol{C}$ sudaryta iš vienetų ir nulių: 


$$
\boldsymbol{C}=\left(\begin{array}{cccc}
1 & 0 & \ldots & 0 \\
0 & 1 & \ldots & 0 \\
\ldots & \ldots & \ldots & \ldots \\
& & & \\
0 & 0 & \ldots & 1
\end{array}\right),
$$

čia stulpelių skaičius $s \leq r$.

Išmatuotų pseudoatstumų sąlyginių lygčiu koeficientų matrica $\boldsymbol{A}$ dèl $r$ epochų ir pavienio palydovo signalų, kai panaudojami trys nešlio kanalai - L1, L2 ir L3, yra tokio kvazidiagonaliojo pavidalo (16), kai joje eilučių skaičius lygus $2 r$, stulpelių - 3r, o $\boldsymbol{A}_{i}=\left(\begin{array}{ccc}1 & -1 & 0 \\ 0 & 1 & -1\end{array}\right)-i$-osios epochos blokinè matrica, $i=1,2, \ldots, r$.

Išmatuotų pseudoatstumų vektoriaus $\boldsymbol{R}(t)$, taikant tris nešlio dažnius, svorių matrica $\boldsymbol{P}_{R}^{\prime}$ yra ịstrižinè:

$$
\boldsymbol{P}_{R}=\left(\boldsymbol{P}_{1}, \boldsymbol{P}_{2}, \ldots \boldsymbol{P}_{r}\right)_{d i a g}
$$

čia eilučiu ir stulpeliu skaičius vienodas ir lygus $3 r$, o $\boldsymbol{P}_{i}=(1,00 ; 0,368 ; 0,310)_{\text {diag }}, i=1,2, \ldots, r$.

\section{Nešlio fazių variantas}

Analogiškos struktūros (3) sąlyginių pataisų lygčiu sistemą galima sudaryti nešlio fazių skirtumu $\Phi_{i, a}^{k}(t)$ matavimu rezultatus redukavus ilgio vienetais (pagal $r$ epochų ir vieno palydovo signalų, kai naudojami $L 1$ ir $L 2$ kanalai, matavimo rezultatus):

$$
A \mathbf{v}_{\Phi}+C \cdot \tau+\omega=0
$$

čia $\mathbf{v}_{\Phi}-$ faziu ciklu pataisu vektorius; $\boldsymbol{\omega}=\boldsymbol{A} \cdot \boldsymbol{\Phi}(t), \boldsymbol{\Phi}(t)=\left\{\boldsymbol{\Phi}_{1}^{T}(t), \boldsymbol{\Phi}_{2}^{T}(t)\right\}$.

Fazių skirtumų ciklai, redukuoti ilgio vienetais, užrašomi lygybe

$$
\Phi_{i, a}^{k}(t)=\lambda_{i} \Phi_{i, a}^{k}(t)
$$

Tais pačiais simboliais pažymètų pavienių matricų reikšmė pseudoatstumų ir nešlio fazių matavimu variantuose yra skirtinga. Tačiau tai neturi sudaryti keblumų skaitant tekstą, nes kiekvieno varianto prasmè ir rezultatai yra skirtingi.

Sąlyginių nešlio fazių skirtumų pataisų lygčių sistemai (19) spręsti taikomos analogiškos formulès kaip ir pseudoatstumų matavimų rezultatams apdoroti (4-11).

Pataisų vektorius $\mathbf{v}_{\Phi}$ yra lygus

$$
\mathbf{v}_{\Phi}=P_{\Phi}^{-1} A^{T} k \text {. }
$$

Koreliatu ir sisteminguju parametrų vektoriai skaičiuojami iš lygybès

$$
\left(\begin{array}{l}
\boldsymbol{k} \\
\boldsymbol{\tau}
\end{array}\right)=-\left(\begin{array}{c}
\boldsymbol{N}^{-1}-\boldsymbol{N}^{-1} \boldsymbol{C} \boldsymbol{N}_{C}^{-1} C^{T} N^{-1} \\
\boldsymbol{N}_{\boldsymbol{C}}^{-1} C^{T} N^{-1}
\end{array}\right) \boldsymbol{\omega}
$$

čia $N_{C}=C^{T} N^{-1} C$.

Išlygintų redukuotų nešlio fazių vektoriaus $\tilde{\Phi}(t)$ reikšmė gaunama iš lygybès:

$$
\tilde{\boldsymbol{\Phi}}(t)=\boldsymbol{\Phi}(t)+\mathbf{v}_{\boldsymbol{\Phi}}=\boldsymbol{\Phi}(t)+\boldsymbol{P}_{\boldsymbol{\Phi}}^{-1} \boldsymbol{A}^{T} \boldsymbol{k},
$$

o kovariacijų matrica $K_{\tilde{\Phi}}$, taikant formulę (15), yra lygi:

$$
\boldsymbol{K}_{\tilde{\boldsymbol{\Phi}}}=\sigma_{0}^{2}\left(\boldsymbol{P}_{\boldsymbol{\Phi}}^{-1}-\boldsymbol{P}_{\boldsymbol{\Phi}}^{-1} \boldsymbol{A}^{T} \boldsymbol{H} \boldsymbol{A} \boldsymbol{P}_{\boldsymbol{\Phi}}^{-1}\right)=\sigma_{0}^{2} \boldsymbol{Q}_{\tilde{\boldsymbol{\Phi}}}
$$

čia $H=N^{-1}-N^{-1} C N_{c}^{-1} C^{T} N^{-1}$.

Matuojant nešlio fazes matricų $A$ ir $C$ išraiška analogiška kaip ir matuojant pseudoatstumus. Svorių matrica $P_{\Phi}$ dviejų nešlio dažnių taikymo variante yra [3]:

$$
\boldsymbol{P}_{\Phi}=\left(\boldsymbol{P}_{1}, \boldsymbol{P}_{2}, \ldots, \boldsymbol{P}_{r}\right)_{\text {diag. }},
$$

čia $P_{i}=(1,00 ; 0,606)_{\text {diag. }}, i=1,2, \ldots, r$.

Svorių matrica $P_{\Phi}$ dèl trijų nešlio dažnių turi tokią išraišką:

$$
\boldsymbol{P}_{\Phi}=\left(\boldsymbol{P}_{1}, \boldsymbol{P}_{2}, \ldots, \boldsymbol{P}_{r}\right)_{\text {diag }},
$$

čia $\boldsymbol{P}_{i}=(1,00 ; 0,606 ; 0,559)_{\text {diag }}, i=1,2, \ldots, r$.

\section{Siūlomo metodo praktinio taikymo rezultatai}

Paprastu pavyzdžiu parodysime, kaip kinta pseudoatstumų pataisos, kai skaičiavimų procedūrose taikomi ir netaikomi papildomi parametrai sistemingosioms klaidoms eliminuoti.

\section{Dviejų nešlio kanalų $-L 1, L 2$ variantas}

Trijų epochų ir vieno palydovo signalų atveju, kai taikomi sistemingieji parametrai, sąlyginių lygčių koeficientų matrica $\boldsymbol{A}$ ir papildomų parametrų koeficientų matrica $\boldsymbol{C}$ (kai taikytas vienas parametras) yra lygios:

$$
\boldsymbol{A}=\left(\begin{array}{cccccc}
1 & -1 & 0 & 0 & 0 & 0 \\
0 & 0 & 1 & -1 & 0 & 0 \\
0 & 0 & 0 & 0 & 1 & -1
\end{array}\right), \boldsymbol{C}^{T}=\left(\begin{array}{lll}
1 & 1 & 1
\end{array}\right),
$$

o atvirkštinių svorių matrica -

$$
\boldsymbol{P}_{R}^{-1}=\left(\boldsymbol{P}_{1}^{-1}, \boldsymbol{P}_{2}^{-1}, \boldsymbol{P}_{3}^{-1}\right)_{\text {diag }},
$$

čia $\boldsymbol{P}_{i}^{-1}=(1,00 ; 2,72)_{\text {diag }}, i=1,2,3$. 
Normalinių lygčių koeficientų matrica $N_{0}$ yra lygi

$$
\begin{aligned}
& \boldsymbol{N}_{0}=\boldsymbol{A}_{0} \boldsymbol{P}_{R}^{-1} \boldsymbol{A}_{0}^{T}=(\boldsymbol{A C}) \boldsymbol{P}_{R}^{-1}(\boldsymbol{A C})^{T}= \\
& =\left(\begin{array}{ccc|c|c}
3,72 & 0 & 0 & 1 \\
0 & 3,72 & 0 & 1 \\
0 & 0 & 3,72 & 1 \\
\hline 1 & 1 & 1 & 0
\end{array}\right),
\end{aligned}
$$

o atvirkštinè matrica

$$
N_{0}^{-1}=\left(\begin{array}{ccc|c}
0,18 & -0,09 & -0,09 & 0,33 \\
-0,09 & 0,18 & -0,09 & 0,33 \\
-0,09 & -0,09 & 0,18 & 0,33 \\
\hline 0,33 & 0,33 & 0,33 & -1,23
\end{array}\right) .
$$

Koreliatų ir sistemingujų parametrų vektorius

$$
\begin{aligned}
& \left(\begin{array}{l}
\boldsymbol{k} \\
\boldsymbol{\tau}
\end{array}\right)=\left(\begin{array}{l}
k_{1} \\
k_{2} \\
k_{3} \\
\tau
\end{array}\right)=-N_{0}^{-1}\left(\begin{array}{c}
\omega_{1} \\
\omega_{2} \\
\omega_{3} \\
0
\end{array}\right)= \\
& =-\left(\begin{array}{c}
0,18 \omega_{1}-0,09 \omega_{2}-0,09 \omega_{3} \\
-0,09 \omega_{1}+0,18 \omega_{2}-0,09 \omega_{3} \\
-0,09 \omega_{1}-0,09 \omega_{2}+0,18 \omega_{3} \\
0,33 \omega_{1}+0,33 \omega_{2}+0,33 \omega_{3}
\end{array}\right) .
\end{aligned}
$$

Išmatuotų pseudoatstumų $R_{i, a}^{k}(t)$ pataisų vektorius $\mathbf{v}_{R}$, kai taikomi sistemingieji parametrai, yra lygus

$$
\begin{aligned}
& \mathbf{v}_{R}=\boldsymbol{P}_{R}^{-1} \boldsymbol{A}^{T} \boldsymbol{k}=\left(\begin{array}{ccc}
1,0 & 0 & 0 \\
-2,72 & 0 & 0 \\
0 & 1,0 & 0 \\
0 & -2,72 & 0 \\
0 & 0 & 1,0 \\
0 & 0 & -2,72
\end{array}\right)\left(\begin{array}{l}
k_{1} \\
k_{2} \\
k_{3}
\end{array}\right)= \\
& =\left(\begin{array}{c}
k_{1} \\
-2,72 k_{1} \\
k_{2} \\
-2,72 k_{2} \\
k_{3} \\
-2,72 k_{3}
\end{array}\right) .
\end{aligned}
$$

Netaikant sistemingujų parametrų, išmatuotų pseudoatstumų pataisų vektorius $\mathbf{v}_{R}^{\prime}$ yra lygus

$$
\mathbf{v}_{R}^{\prime}=\boldsymbol{P}_{R}^{-1} \boldsymbol{A}^{T} \boldsymbol{k}^{\prime}=\left(\begin{array}{c}
-0,26 \omega_{1} \\
0,74 \omega_{1} \\
-0,26 \omega_{2} \\
0,74 \omega_{2} \\
-0,26 \omega_{3} \\
0,74 \omega_{3}
\end{array}\right) \text {, }
$$

čia $\boldsymbol{k}^{\prime}=-\boldsymbol{N}^{-1} \boldsymbol{\omega}=\left(-0,27 \omega_{1},-0,27 \omega_{2},-0,27 \omega_{3}\right)^{T}$.

Palygindami vektorių $\mathbf{v}_{R}$ ir $\mathbf{v}_{R}^{\prime}$, gautų taikant ir netaikant sisteminguosius parametrus, išraiškas matome, kad jie gana akivaizdžiai skiriasi. Taigi atsižvelgiant i tai, kad matavimų sistemingosios klaidos yra neišvengiamos, tikslinga GPS matavimo rezultatų apdorojimo procedūrose taikyti papildomus nežinomuosius sistemingujų parametrų pavidalu.

\section{Trijų nešlio kanalų - L1, L2 ir $L 3$ variantas}

Pateiksime pavyzdi, kaip esti taikant tris nešlio kanalus - L1, L2 ir $L 3$, kai naudojami trijų epochų vieno palydovo signalai. Sistemingujų parametrų taikymo variante, kai naudotas vienas parametras, galime parašyti šias matricas:

$$
\begin{aligned}
& \boldsymbol{A}=\left(\begin{array}{lll}
\boldsymbol{A}_{1} & \boldsymbol{A}_{2} & \boldsymbol{A}_{3}
\end{array}\right)_{\text {diag }}, \boldsymbol{A}_{i}=\left(\begin{array}{ccc}
1 & -1 & 0 \\
0 & 1 & -1
\end{array}\right), \\
& \boldsymbol{C}=\left(\begin{array}{llllll}
1 & 1 & 1 & 1 & 1 & 1
\end{array}\right)^{T}, \boldsymbol{P}_{R}^{-1}=\left(\begin{array}{lll}
\boldsymbol{P}_{1}^{-1} & \boldsymbol{P}_{2}^{-1} & \boldsymbol{P}_{3}^{-1}
\end{array}\right)_{\text {diag }}, \\
& \boldsymbol{P}_{i}^{-1}=\left(\begin{array}{lll}
1,00 ; & 2,72 ; & 3,23
\end{array}\right)_{\text {diag. }}, \mathrm{i}=1,2,3 .
\end{aligned}
$$

Normalinių lygčių koeficientų matrica $N_{0}$ užrašoma taip:

$$
\boldsymbol{N}_{0}=\boldsymbol{A}_{0} \boldsymbol{P}_{R}^{-1} \boldsymbol{A}_{0}^{T}=(\boldsymbol{A C}) \boldsymbol{P}_{R}^{-1}(\boldsymbol{A C})^{T}=\left(\begin{array}{cc}
\boldsymbol{N} & \boldsymbol{C} \\
\boldsymbol{C}^{T} & 0
\end{array}\right),
$$

čia $N=\left(\begin{array}{lll}N_{1} & N_{2} & N_{3}\end{array}\right)_{\text {diag }}$,

$$
\boldsymbol{N}_{i}=\boldsymbol{A}_{i} \boldsymbol{P}_{i}^{-1} \boldsymbol{A}_{i}^{T}=\left(\begin{array}{cc}
3,72 & -2,72 \\
-2,72 & 5,95
\end{array}\right), i=1,2,3 .
$$

Koreliatų ir sisteminguju parametrų vektorius

$$
\left(\begin{array}{l}
\overline{\boldsymbol{k}} \\
\boldsymbol{\tau}
\end{array}\right)=-N_{0}^{-1}\left(\omega_{1}, \omega_{1}^{\prime}, \omega_{2}, \omega_{2}^{\prime}, \omega_{3}, \omega_{3}^{\prime}, 0\right)^{T}
$$

čia $\omega_{i}, \omega_{i}^{\prime}-i$-osios epochos sąlyginiu pataisu lygčiu nesąryšiai, taikant atitinkamus L1, L2 ir L3 kanalų derinius.

Toliau gauname: 


$$
\left(\begin{array}{c}
\overline{\boldsymbol{k}} \\
\boldsymbol{\tau}
\end{array}\right)=-\left(\begin{array}{c}
0,29 \omega_{1}+0,10 \omega_{1}^{\prime}-0,11 \omega_{2}-0,08 \omega_{2}^{\prime}-0,11 \omega_{3}-0,08 \omega_{3}^{\prime} \\
\frac{0,10 \omega_{1}+0,19 \omega_{1}^{\prime}-0,08 \omega_{2}-0,06 \omega_{2}^{\prime}-0,08 \omega_{3}-0,06 \omega_{3}^{\prime}}{-0,11 \omega_{1}-0,08 \omega_{1}^{\prime}+0,29 \omega_{2}+0,10 \omega_{2}^{\prime}-0,11 \omega_{3}-0,08 \omega_{3}^{\prime}} \\
\frac{-0,08 \omega_{1}-0,06 \omega_{1}^{\prime}+0,10 \omega_{2}+0,19 \omega_{2}^{\prime}-0,08 \omega_{3}-0,06 \omega_{3}^{\prime}}{-0,11 \omega_{1}-0,08 \omega_{1}^{\prime}-0,11 \omega_{2}-0,08 \omega_{2}^{\prime}+0,29 \omega_{3}+0,10 \omega_{3}^{\prime}} \\
\frac{-0,08 \omega_{1}-0,06 \omega_{1}^{\prime}-0,08 \omega_{2}-0,06 \omega_{2}^{\prime}+0,10 \omega_{3}+0,19 \omega_{3}^{\prime}}{0,19 \omega_{1}+0,14 \omega_{1}^{\prime}+0,19 \omega_{2}+0,14 \omega_{2}^{\prime}+0,19 \omega_{3}+0,14 \omega_{3}^{\prime}}
\end{array}\right) .
$$

Išmatuotų pseudoatstumų $R_{i, a}^{k}(t)$ pataisų vektoriaus $\overline{\mathbf{v}}_{R}$, esant trims nešlio kanalams ir taikant vieną papildomą parametrą, išraiška:

$$
\overline{\mathbf{v}}_{R}=\boldsymbol{P}_{R}^{-1} \boldsymbol{A}^{T} \overline{\boldsymbol{k}}=\left(\begin{array}{c}
k_{1} \\
-2,72 k_{1}+2,72 k_{2} \\
-3,23 k_{2} \\
k_{3} \\
-2,72 k_{3}+2,72 k_{4} \\
-3,23 k_{4} \\
k_{5} \\
-2,72 k_{5}+2,72 k_{6} \\
-3,23 k_{6}
\end{array}\right) .
$$

Netaikant sistemingujų parametru, išmatuotu pseudoatstumu pataisų vektorius $\overline{\mathbf{v}}_{R}^{\prime}$, kai naudojami $L 1$, $L 2$ ir $L 3$ nešlio kanalai, yra lygus

$$
\overline{\mathbf{v}}_{R}^{\prime}=P_{R}^{-1} A^{T} \bar{k}=\left(\begin{array}{c}
0,40 \omega_{1}+0,18 \omega_{1}^{\prime} \\
-0,60 \omega_{1}+0,19 \omega_{1}^{\prime} \\
0,40 \omega_{2}+0,18 \omega_{2}^{\prime} \\
-0,60 \omega_{2}+0,19 \omega_{2}^{\prime} \\
0,40 \omega_{3}+0,18 \omega_{3}^{\prime} \\
-0,60 \omega_{3}+0,19 \omega_{3}^{\prime}
\end{array}\right) .
$$

\section{Metodo tikslumo ịvertinimas}

Taikydami formulę (15) anksčiau pateiktiems pavyzdžiams apskaičiuojame išlygintų pseudoatstumu vektoriaus $\tilde{\boldsymbol{R}}(t)$ svorines matricas $\boldsymbol{Q}_{\tilde{R}}$ dvieju ir triju nešlio dažniu variantuose, kai skaičiavimų procedūrose taikytas ir netaikytas sistemingasis parametras. Pateiksime tik svorinių matricu $\boldsymbol{Q}_{\tilde{R}}$ istrižinius narius, nes jie apibrèžia išlygintų pseudoatstumų atvirkštinius svorius:

$$
\boldsymbol{Q}_{\tilde{R}, i i}=\left(\boldsymbol{P}_{R}^{-1}-\boldsymbol{P}_{R}^{-1} \boldsymbol{A}^{T} \boldsymbol{H} \boldsymbol{A} \boldsymbol{P}_{R}^{-1}\right)_{i i} .
$$

Dviejų nešlio dažnių variante turime:

$$
\boldsymbol{Q}_{\tilde{R}, i i}=\left(\begin{array}{llllll}
0,82 & 1,40 & 0,82 & 1,40 & 0,82 & 1,40
\end{array}\right)_{i i}-
$$

taikant sistemingaji parametra,

$$
\boldsymbol{Q}_{\tilde{R}, i i}^{\prime}=\left(\begin{array}{llllll}
0,73 & 0,72 & 0,73 & 0,72 & 0,73 & 0,72
\end{array}\right)_{i i}^{-}
$$

netaikant sistemingojo parametro.

Trijų nešlio dažnių atveju gauname:

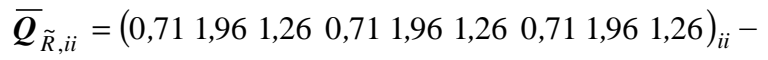
taikant sistemingaji parametrą,

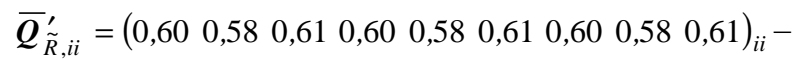
netaikant sistemingojo parametro.

Kovariacijų matricos $\boldsymbol{K}_{\tilde{R}}$ ivertis gaunamas, kai vietoje $\sigma_{0}$ taikomas jo įvertis $m_{0}$ :

$$
\boldsymbol{K}_{\tilde{R}}^{\prime}=m_{0}^{2} \boldsymbol{Q}_{\tilde{R}} .
$$

Standartinio nuokrypio įvertis $m_{0}$ skaičiuojamas pagal formules:

$$
m_{0}^{2}=\frac{1}{r_{s}}\left(\boldsymbol{V}_{R}^{T} \boldsymbol{P}_{R} \boldsymbol{V}_{R}-\boldsymbol{\tau}^{T} \boldsymbol{C}^{T} \boldsymbol{N}^{-1} \boldsymbol{C} \boldsymbol{\tau}\right)_{-}
$$

taikant sisteminguosius parametrus,

$$
m_{0}^{2}=\frac{1}{r} V_{R}^{T} P_{R} V_{R}-
$$

netaikant sistemingujų parametru,

čia $r_{s}=r-s$.

Skaičiavimų rezultatai rodo, kad svorinių matricu instrižiniai nariai $\boldsymbol{Q}_{\tilde{R}, i i}$ yra mažesni tuo atveju, kai netaikomi sistemingieji parametrai. Tačiau $m_{0}$ reikšmė šiuo atveju yra didesnè, tai rodo formulès (26), (27). Todèl kovariacijų matricos ịverčio $\boldsymbol{K}_{\tilde{R}}$ istrižiniai nariai bus mažesni taikant sisteminguosius parametrus. 


\section{Išvados}

1. Pateikiamos formulès (9), (11), (21), (22) išmatuotų pseudoatstumų ir nešlio fazių skirtumu pataisoms skaičiuoti, taikant sisteminguosius parametrus. Gautos išlygintų pseudoatstumų ir nešlio fazių skirtumu kovariacijų matricų formulès (15), (24).

2. Praktinių skaičiavimų rezultatai, taikant du ir tris nešlio dažnius, parodè, kad sistemingujų klaidų itaka gali būti pakankamai akivaizdi, tačiau ją galima eliminuoti arba sumažinti matavimų apdorojimo procedūrose taikant papildomus sisteminguosius parametrus.

\section{Literatūra}

1. Bauer, M. Vermessung und Ortung mit Satelliten. Heidelberg: Wichmann, 1994. 274 S.

2. Hofmann-Wellenhof, B.; Lichtenegger, H. and Collins, J. Global Positioning System. In: Theory and Practice. Wien, New York: Springer-Verlag, 1992. 326 p.

3. Leick, A. GPS Satellite Surveying. New York, Chichester, Brisbane, Toronto, Singapore: John Wiley and Sons. 1995. $352 \mathrm{p}$.

4. Koch, K. R. Einführung in die Bayes-Statistik. SpringerVerlag Berlin Heidelberg, 2000. 225 S.

5. Teunissen, P. J. G. An optimality property of the integer least-squares estimator. Journal of Geodesy, No 73. Berlin: Springer-Verlag, 1999 b, p 275-284.

6. P. Petroškevičius. Gravitation field effect on geodetic observations. (Gravitacijos lauko poveikis geodeziniams matavimams). Vilnius: Technika, 2004. 292 p (in Lithuanian).
7. Hankemeier, P. Der Satellitenpositionierungsdienst SAPOS in Deutschland. Multifunktionale GNSSReferenzstationsysteme für Europa. Workshop von 4. 5. März 2002 in der Europäischen Akademie für städtische Umwelt. Berlin, S. 16-23.

8. Skeivalas, J. Accuracy of GPS observations linear models (GPS matavimu tiesiniu modelių tikslumas). Geodesy and Cartography (Geodezija ir kartografija), Vol XVIII, No 2, Vilnius: Technika, 2002, p 35-38 (in Lithuanian).

9. Skeivalas, J. Construction of linear models of pseudoranges and carrier phases for eliminating the ionosphere influence (Pseudoatstumų ir nešlio fazių tiesinio modelio jonosferos itakai eliminuoti sudarymas). Geodesy and Cartography (Geodezija ir kartografija), Vol XXIX, No 3, Vilnius: Technika, 2003, p 61-64 (in Lithuanian).

10. Skeivalas, J. Treatment of correlated geodetic measurements results (Koreliuotu geodeziniu matavimu rezultatu matematinis apdorojimas). Vilnius: Technika, 1995. 272 p (in Lithuanian). 